Canadian University Music Review

Revue de musique des universités canadiennes

\title{
On the Recruitment Process in Amateur Ensembles
}

\section{Estelle R. Jorgensen}

Numéro 6, 1985

URI : https://id.erudit.org/iderudit/1014041ar

DOI : https://doi.org/10.7202/1014041ar

Aller au sommaire du numéro

\section{Éditeur(s)}

Canadian University Music Society / Société de musique des universités canadiennes

\section{ISSN}

0710-0353 (imprimé)

2291-2436 (numérique)

Découvrir la revue

\section{Citer cet article}

Jorgensen, E. R. (1985). On the Recruitment Process in Amateur Ensembles. Canadian University Music Review / Revue de musique des universités

canadiennes, (6), 293-318. https://doi.org/10.7202/1014041ar

(c) Canadian University Music Society / Société de musique des universités canadiennes, 1985
Ce document est protégé par la loi sur le droit d'auteur. L'utilisation des services d'Érudit (y compris la reproduction) est assujettie à sa politique d'utilisation que vous pouvez consulter en ligne.

https://apropos.erudit.org/fr/usagers/politique-dutilisation/ 


\title{
ON THE RECRUITMENT PROCESS IN AMATEUR ENSEMBLES
}

\author{
Estelle R. Jorgensen
}

The social process of recruitment is of fundamental importance in the formation and maintenance of ensembles, and this is especially true of amateur ensembles. ${ }^{1}$ Unlike professional ensembles, in which financial inducements and a possible livelihood are offered to members, amateur ensembles must rely on academic, prestigious, social, musical, and other hedonistic rewards to attract members, and recruitment strategies take on added significance as a result. ${ }^{2}$

My present purpose is to provide a systematic theoretical analysis of the recruitment process in amateur ensembles, cast at a level of generality that transcends institutional differences (including those among the various sponsoring organizations, e.g., schools, churches, community groups), and the differences between genres of ensembles (e.g., bands, choirs, orchestras); an analysis that is potentially useful as a conceptual framework for subsequent empirical research, and in the solution of various recruitment problems faced by ensemble directors.

The analysis is based on several assumptions. First, the term "ensemble" is used in a restrictive sense, to refer to an amateur musical ensemble such as a band, choir, or orchestra requiring a director or conductor. ${ }^{3}$

Second, the director is free to determine ensemble membership, repertoire, rehearsals, and performances, and the members are not coerced into the ensemble but may enter and leave by their own volition. ${ }^{4}$

Third, the ensemble is in a continual dynamic state of "becoming" or evolving as a social organization. It represents 
principles of growth and atrophy analogous to those in the physical world. The societal context in which the ensemble is situated is also in a dynamic state of becoming. These forces of evolution between the ensemble and its environment interact in a dynamic process. Societal values, for example, may change over time. The ensemble is responsive to these changes and, in turn, feeds them.

Fourth, the ensemble freely interacts with its environment without external interference, that is, no outside organization, be it church, government, or other agency, prevents the normal evolution of the ensemble or its interaction with the environment through time. This assumption constitutes a useful delimination for the present analysis, in that it enables speculation about causal factors principally arising within the ensemble rather than outside it.

Fifth, there are five conceptually distinct phases in the development or "life cycle" of an ensemble, each of which exemplifies a corresponding profile of recruitment strategies. These are shown in Figure 1, with time represented on the $\mathrm{X}$ axis (e.g., in number of years) and the growth of the ensemble on the $Y$ axis (e.g., depicted by a variety of indices, notably, the reputation or prestige of the ensemble). The formation phase marking the beginning of the ensemble is followed by an expansion phase and then by a maturation phase where the ensemble is no longer able to adjust to its environment and decay sets in, leading to cessation or the demise of the ensemble. These phases have their counterpoint in the physical world where all things are born, grow, mature, decay, and die. As well, they are paralleled in social-psychology, for example, in the five phases of close relationships recognized in the work of George Levinger (1980) as follows: initial attraction, building the relationship, continuation, deterioration, and ending.

These phases are types, or theoretical constructs that are systematically compared according to given characteristic dimensions. They need not follow in order (e.g., regression may follow expansion or vice versa), and phases may be omitted. Over the long term, however, the ensemble moves from formation to cessation, that is, its "life" is finite. While Figure 1 may appear simplistic when compared with the real world, it serves a useful purpose in clarifying the essence of the conceptual distinctions between the five ensemble development phases. ${ }^{5}$

The analysis proceeds in two steps: first, the description of each of the ensemble development phases; and second, the 
derivation of recruitment strategies consistent with conditions in each phase.

I turn now to a systematic description of the characteristic profile for each ensemble development phase, based on the assumptions listed above. In tackling this problem, I will draw on a list of six dimensions that are common to all social systems, namely, time, space, number, causation, ethics, and aesthetics. ${ }^{6}$ These dimensions enable a systematic comparison of social events, and as such, they are useful theoretical tools in the present analysis. A profile of characteristics for each ensemble development phase emerges as various aspects of these dimensions are described in turn, using hypothetical examples for each phase. Figure 2 is a summary of the characteristics of the ensemble development phases and provides a useful overview of the subsequent analysis. It should be read linearly for each dimension, as the descriptive terms that are used denote comparative rather than absolute statements, that is, they should be judged relative to terms used for the same dimension.

\section{Time}

The dimension of time refers to when events transpire, not only with reference to clock-time, but also psychologicallyperceived and social time as well. There are three principal functions of ensembles, among others, that are constrained in time, namely, rehearsals, performances, and the admission of new members.

In the formation phase, rehearsal time is not well-defined. It may well depend, to some degree, on the individuals who initially form the ensemble. For example, the director may plan an ensemble season of a certain length, with rehearsals of given duration to be held at certain times in the week, but members may wish to rehearse at other times, and they may feel that the director's rehearsal schedule is either too time-consuming or insufficient for their needs. Here, there is potential for change. As the ensemble reaches the expansion phase, there is increasing definition of rehearsal time. On the basis of past experience, members have more clearly formed expectations about the time commitment to rehearsals. In the maturation phase, these 
expectations are well-defined. The rehearsal time commitment adjusts to the expectations of ensemble members and to the demands of performance commitments. In the regression phase, as the ensemble deteriorates, the rehearsal time decreases in definition. This may be due to a variety of factors. The director may make rehearsal demands on members that are unrealistic, not attainable by them, or that they are unwilling to accept. Changes in previously established expectations may also result in a decreasing definition of rehearsal time commitments. For example, as it becomes more difficult to assemble a quorum of members at rehearsals, additional "make-up" rehearsals may be necessary, changing the time commitments for the members. In the cessation phase, members cannot or will not adjust to the rehearsal time demands and they leave the ensemble.

In the formation phase, the performance schedule is not well defined, but partly depends upon the calibre of individuals initially attracted to the ensemble. Members bring skills to the ensemble that contribute to a unique whole. The complexion of these talents and skills will vary, influencing the repertoire to be performed and the performance schedule that is feasible. During the expansion phase, expectations about performance schedules become more clearly defined. As members are recruited into the ensemble, the potential of the organization becomes clearer and the possibilities for performance better defined. In the maturation phase, expectations are clearly established. The members accept the demands of the concert season and there is consensus that these demands are realistic. In the regression phase, the demands become more unrealistic. Members may feel, for example, that there is insufficient rehearsal time to prepare the repertoire for the performance schedule. There may be developments in the community or the ensemble membership that result in a loss of key members and a change in the complexion of the group, making the planned performance schedule unrealistic. An inability of the ensemble to adjust to changes in its environment results in a decreasing consensus about the performance schedule and a decreasing definition in members' expectations of it. In the cessation phase, there is a loss of confidence in the ability to predict the performance schedule, and as expectations become ill-defined, members leave the ensemble so that it ceases to exist.

In the formation phase, the schedule for admitting new members is ill-defined. There is a high demand for members to form the ensemble and comparatively little disruption by 
introducing new members into the group. They are accepted whenever they can be found, and there is a minimum of structure in the times at which openings in ensemble places are advertised and new members are accepted. As the expansion phase is reached, the projected size of the enemble becomes more clearly established, and expectations about the scheduling of openings are better defined. In the maturation phase, the rules respecting the timing of auditions and the acceptance of new members are clearly established, and it is generally known that new members will be accepted at the beginning of the rehearsal season or at specified times throughout the year. In the regression phase, as members begin to leave the ensemble and morale deteriorates, the recruitment of new members becomes a more pressing concern and they are increasingly introduced into the ensemble whenever they can be found, thereby disrupting the group organization. Expectations about the rules for admitting new members become less clearly defined. In the cessation phase, the ensemble is disrupted by the high turnover throughout the concert season, and members eventually leave so that the ensemble ceases to exist.

\section{Space}

The dimension of space refers to where events transpire; their location in geographic, physical space as well as in psychologically-perceived and social space. There are three principal functions of ensembles, among others, that are constrained in space, namely, the ensemble feeder area, the ensemble feeder system, and external competition for members.

The feeder area, or the spatial area from which the ensemble draws its members, is a relative one, depending on the transportation facilities available in the area and the resources of the members enabling them to afford the financial and time commitments involved. Presumably, the greater the prestige and influence of the ensemble and the greater its attractiveness to members, the more sacrifices they will make to attend rehearsals and performances. In the formation phase, the feeder area is relatively small. Potential members are reluctant to sacrifice to attend rehearsals and performances. As the ensemble reaches the expansion phase, the feeder area widens, as members are willing to make greater sacrifices in order to participate in the ensemble. At maturation, the feeder area is comparatively large and welldefined. In the regression phase, morale declines and individuals are willing to make fewer sacrifices to maintain membership in the 
ensemble. If they had been willing to travel a comparatively long distance before, they now find it increasingly irksome and difficult to be regularly present at rehearsals and performances. The feeder area shrinks until, at the cessation phase, it is a comparatively small one and members leave the ensemble when they are sufficiently inconvenienced.

The feeder system, or the organizational network that the ensemble has developed to ensure a continued supply of new members, pre-supposes a preparatory system of training in more elementary ensembles; the organization of a network (formal or informal) in which the ensemble's influence is felt and from which it can reasonably be expected to draw new members. At the formation phase, the feeder system is comparatively ill-defined. The ensemble is struggling to survive and its preoccupation is with attracting members now, rather than in the more distant future. Until it establishes a level of credibility, the ensemble is not in a position to set up a formal network through which new members will be attracted. There is a lag between the time new members join the ensemble and the time at which they recruit other members, depending on their experiences in rehearsals and performances, and the opinions of valued "others" on the ensemble rehearsals and performances. As the ensemble reaches the expansion phase, expectations are increasingly better defined, both on the part of members and others outside the ensemble. There is a corresponding emphasis on the systematic recruitment of members and an orientation toward long range planning rather than immediate survival. In the maturation phase, expectations are well established, and formal and informal networks are established for the recruitment of new members. During regression, there is a disintegration of the feeder system for the ensemble as previously held expectations are no longer sustained. At the cessation phase, the established feeder system breaks down, and the ensemble's preoccupation is with immediate survival rather than longer-term commitments. Eventually, this process reaches a breaking point where the ensemble ceases to exist.

External competition implies a limited supply of potential ensemble members, and competition from other sources within the environment in which the ensemble is situated, for example, other similar ensembles in the same geographic area or other competing interests for a potential member's time. At the formation phase, external competition with the ensemble is relatively high. The ensemble is not well known, its prestige is not established and it 
must compete with other musical and non-musical organizations and interests in which potential members are involved. As the ensemble enters the expansion phase and becomes better established, its prestige value rises, and it is in a better position to compete for members with organizations and interests in the surrounding environment. External competition also decreases as members become more committed to the ensemble. At maturation, the ensemble is well-known and established. Expectations are clearly formulated on the basis of its past performance. Effective external competition from environmental sources is comparatively low. The mature ensemble now poses as potential competition for other ensembles in the formation and expansion phases. In regression, the ensemble's prestige declines. Expectations based on its past performance are disappointed. Other organizations and priorities increasingly compete for members' participation or attention and there is growing external competition. At cessation, external competition is relatively high as members' commitment falls to the point where they leave the ensemble.

\section{Number}

The dimension of number refers to the the expression of quantity. As such, number represents a constraint upon the ensemble. For example, there are a limited number of musicians who are willing or able to join a given ensemble at any time, and a limited amount of time and space available for rehearsal and performance. There are three pressing numerical constraints on ensembles, among others, namely, the absolute and relative size of the ensemble, the supply of potential members, and the demand for limited ensemble places.

At formation, the size of the ensemble is ill-defined. The individuals who comprise it at the outset partly determine its composition and future direction. The notion of "size" in this context is a relative one. While the director or individuals involved may wish to form an ensemble of a certain size and composition, the unavailability or unwillingness of suitably qualified musicians to fill the ensemble complement may necessitate an alteration in their initial conception. During expansion, there is an increasing definition in the size of the ensemble, and expectations are better defined in the light of past experience. At maturation, the size of the ensemble is well-defined. During the regression phase, however, as morale declines and the turnover rate increases, the concept of optimal ensemble size becomes increas- 
ingly unclear. It may be more difficult to replace the skills of members who leave the ensemble, thereby altering its complexion and optimal size. In cessation, the size of the ensemble is illdefined, and the ensemble disintegrates when it becomes impossible to replace members who have left.

At the formation phase, the supply of available places in the ensemble is relatively large. As the ensemble reaches the expansion phase, the supply of available places diminishes in relation to the possible size of the ensemble. At maturation, the complement of musicians is filled. The relatively high ensemble morale and low turnover rate due to natural attrition result in a comparatively small supply of available openings. In the regression phase, the supply of available places increases due to a higher turnover rate and attrition as more members leave the ensemble. At cessation, this supply of places is relatively high as it becomes increasingly difficult to attract members, and the ensemble eventually breaks down.

In the formation phase, the demand for available places in the ensemble is relatively small. The ensemble is not well-known, its prestige value is relatively low, and there is little competition for ensemble places by virtue of their large supply. As the ensemble reaches the expansion phase, the supply of available places decreases and there is greater competition for them, increasing their prestige value and, in turn, the demand for them. The expectations concerning the ensemble stabilize and demand continues to increase. At maturation, there is a large demand for places in the ensemble, partly due to the high prestige value of membership and the small supply of available places. In the regression phase, the demand for membership in the ensemble falls as expectations are disappointed, morale diminishes, and the prestige value declines. It eventually reaches a low level in the cessation phase, such that the ensemble cannot maintain itself and ceases to exist.

\section{Causation}

The dimension of causation refers to the underlying reasons why events occur, specifically, the factors affecting the willingness of musicians to participate in the ensemble, partly due to the response from those who are outside it, for example, friends, professional colleagues, or music critics. These psychological and social factors constitute causal determinants in the ensemble's development. There are six important aspects of causation in 
ensembles, among others, namely, community interest, ensemble morale, motivation, response, image, and prestige.

Community interest refers to the response to the ensemble by relevant "others," not members of the ensemble. This is a relative concept and construed to refer to the specific elements of concern to members of the ensemble, be they media coverage of concerts, reviews from music critics, the interest and support of a segment of the musical community, or the like. In the formation phase, community interest is relatively low as others outside the ensemble adopt a "wait-and-see" attitude. At the expansion phase, community interest increases as the ensemble consolidates. At maturation, the ensemble is well-known, an established clientele or "following" has developed, and community interest is relatively high. As the ensemble reaches the regression phase, expectations are no longer realized, and community interest declines to a relative low at cessation.

At formation, ensemble morale, or the positive attitudes and feelings of members toward the ensemble, is relatively low. As the ensemble reaches the expansion phase, morale rises. In maturation, ensemble morale is relatively high as members' expectations are realized. During regression, morale falls, partly due to the unrealized expectations of ensemble members, the departure of long-time valued members, and the introduction of new members into the ensemble, disrupting its cohesion and social structure. At cessation, morale falls to a low point where members are discouraged and eventually leave the ensemble.

Motivation refers to the underlying reasons for members to participate in the ensemble, and is of two types: extrinsic, where some external reward for ensemble participation is perceived; and intrinsic, where the ensemble is perceived to be of inherent value. Extrinsic motivation does not sustain long-term membership in an ensemble to the degree engendered by intrinsic motivation, and an individual is prepared to make sacrifices or commitments over the long term only if these bring inherently satisfying rewards, be they musical or social. At the formation phase, when the ensemble morale is comparatively low, or where the ensemble's goals have not as yet been internalized by the members, extrinsic rewards are required. As the ensemble reaches the expansion phase, members are increasingly motivated by intrinsic rewards. At maturation, motivation is primarily intrinsic, and ensemble members have a relatively high morale. During regression, as morale declines and members derive diminishing intrinsic satisfaction from ensemble 
participation, extrinsic motivation is increasingly evident. Eventually, in the cessation phase, members are extrinsically motivated, and they leave the ensemble when the external rewards of membership are insufficient to keep their interest.

In the formation phase, response or the degree to which ensemble participation is based on collective as opposed to individualistic response is primarily collective. As motivation is primarily extrinsic, it matters a great deal whether the "right" people are joining the ensemble. The response is collective, partly because individuals do not know what the ensemble is likely to become, and they tend to wait for others to join first, so that they will be in a better position to judge what external rewards might accrue from taking ensemble membership. As the ensemble reaches the expansion phase, and motivation becomes increasingly intrinsic in character, the response is more individualistic. At maturation, members are primarily motivated by intrinsic values and their response is individualistic. Community interest stabilizes at a relatively high level, expectations concerning the quality and nature of ensemble performance are well-established, and individuals decide on the basis of these facts, whether or not they will be members of the ensemble. During the regression phase, as morale and community interest decrease, extrinsic motivation increases, and members are more aware of community interest and of how valued friends and colleagues are reacting to their membership of the ensemble, individualistic response declines. Increasingly, groups rather than individuals depart from the ensemble. At cessation, the response is primarily collective. Members are aware that expectations of the ensemble's performance have been disappointed and they distinguish their individual talents from the ability of the ensemble conceived of as a collectivity. In view of the ensemble's imminent demise, there is a heightened awareness of this distinction, resulting in a collective response to the necessity of abandoning the ensemble.

Image refers to the ensemble's projection to others outside it, either as the process of personification whereby the ensemble creates an image or organizational personality, or as the process of image preservation whereby the ensemble seeks to maintain its image and preserve its reputation and prestige. ${ }^{7}$ At formation, there is an emphasis on personification. The ensemble's image results partly from the complexion of the membership in the formation phase. During expansion, the emphasis increasingly becomes one of image preservation, until in maturation, this is the 
predominant consideration. Expectations are well-established and the ensemble's performances generally match them. Comparisons are made between past and present performance, and a progression rather than a decline is evident. In regression, there is a decreasing concern with image preservation and an increasing preoccupation with personification and image building, as expectations are increasingly disappointed, community interest diminishes, and knowledge about the ensemble declines. At cessation, members are preoccupied with personification, that is, with the need to redefine the ensemble's image in order to survive.

There are three facets of prestige, namely, prestige value, prestige source, and prestige focus. In the formation phase, prestige value, or the relative degree (or amount) of prestige is relatively low. It is primarily established with reference to the conductor's prestige, although it is also influenced by the nature of the collective response to recruitment and the degree of interest by relevant "others" in the community. As the ensemble moves through the expansion phase, and establishes a reputation in the community, and more widely beyond it, the prestige of the ensemble and that accruing to the ensemble members increases. At maturation, it rises to a relatively high level as the reputation of the ensemble is well-established and expectations concerning its performance are realized. During regression, it declines as expectations concerning ensemble performance are increasingly disappointed. In cessation, it falls to a relative low such that there is insufficient incentive for the members to continue to make the necessary sacrifices in order to remain in the ensemble.

Prestige source refers to the direction from which prestige emanates as between member and ensemble, accruing either to the ensemble as a result of given individuals having joined, or to individuals as a result of their having joined the ensemble. At the formation phase, the individual member is the source of ensemble prestige. With extrinsic motivation and collective response predominant, the individual members who join the ensemble bring it prestige by virtue of their social status, musical training, and past experience, among others. In expansion, as the ensemble acquires a reputation and community interest increases, the source of prestige is increasingly centered in the ensemble. The individual acquires prestige as a result of joining the ensemble, rather than vice versa. In maturation, with high morale, community interest and prestige value, the source of the prestige is centered in the ensemble. During regression, the source of the 
prestige increasingly centers on the individual, as community interest wanes, morale and prestige value fall, and there is a growing response on the part of members to focus the the reasons for the decline of the ensemble upon the collectivity rather than upon themselves as individuals. The ensemble increasingly acquires prestige as a result of individuals joining the ensemble. At cessation, this tendency consolidates. As members are primarily motivated by extrinsic factors, and do not receive sufficiently prestigious rewards from ensemble membership, they eventually leave and the ensemble disintegrates.

Prestige focus, or the focus of prestige as between conductor and ensemble, accrues as a result of the reputation of either the conductor or the ensemble. At the formation phase, the focus of prestige is on the conductor or director. It is largely his or her reputation that attracts members to the ensemble, and influences the ease of recruiting members and the initial quality of the ensemble. During the expansion phase, the ensemble's reputation becomes better established and the focus of prestige moves from the conductor to the ensemble. At maturation, prestige is focused on the ensemble, and the conductor acquires prestige as a consequence of directing the ensemble. The ensemble's reputation is well-established, and it is not tied to the charismatic personality of any one individual, but is capable of surviving under a succession of conductors. In regression, members begin looking for persons on whom to affix "blame" for the ensemble's decline, and focus of prestige becomes increasingly conductor-oriented. This process consolidates at cessation, where the focus of prestige is conductor-centered.

\section{Ethics}

The ethical dimension has reference to the system of morally imperative, interpersonal, and intergroup values underlying the operation of a social system. There are seven important ethical aspects of ensembles, among others, namely, values, rules, change orientation, reference group, cooperation, internal competition, and conductor choice.

Values refer to the guiding ideas in the formation of specific organizational rules or norms. There is an important distinction between universalism, that is, the philosophy of inclusiveness based on an all-encompassing view of humankind that denies distinctions between persons on the basis of given criteria (e.g., musical talent, financial wealth, social influence and power), and 
elitism, that is, the philosophy of exclusiveness based on a view of humankind that emphasizes distinctions and classes or subclasses based on given criteria. At the formation phase, the value system is predominantly universalistic. Members are needed to form the ensemble and given the comparatively low prestige value, the director may be forced to accept individuals who under other conditions would be unacceptable, in order to fill the complement of musicians. As the ensemble reaches the expansion phase and the demand for available places increases, the director can afford to be more selective and values become increasingly elitist. At maturation, with relatively high prestige value, the standards of admission are raised and an elitist philosophy prevails. During regression, as the demand for ensemble places declines and prestige value falls, the best musicians leave the ensemble and their places are filled by less qualified persons. It becomes more difficult to fill vacant positions, thereby necessitating an increasingly universalistic approach. At cessation, universalism prevails, along with low prestige value and morale.

At the formation phase, rules, or the normative procedures by which a social group operates, for example, law, policies, and due process, are ill-defined. As the ensemble reaches the expansion phase, procedures become standardized. Precedents are established on the basis of past experience and expectations stabilize. Procedures in auditions, allocation of administrative responsibilities (e.g., advertising, concert management, music library operation, financial control, social activities), rehearsals, and performances, among others, are defined. At maturation, they are well-known, accepted by the members, and form the basis on which expectations are based. In regression, these procedures begin to break down. Individuals who have held key positions leave the ensemble and are not adequately replaced. Increasing universalism and the necessity for accepting members of inferior quality results in a further breakdown of procedures in such areas as auditions, rehearsals, and performances. For example, there may be an increasing disparity between the expectations of the number and quality of ensemble performances, and the ensemble's ability to deliver, resulting in growing pressure to modify the rules governing ensemble performances. Eventually, at cessation, the organizational rules break down. Members are disenchanted with the ensemble, their morale is low, and they leave the ensemble bringing about its demise.

Change orientation refers to the degree to which the ensemble 
is geared toward change rather the status quo. In the formation phase, the ensemble is preoccupied with present survival rather than with future development. As the expansion phase is reached, there is a growing orientation toward change. Prestige value increases, the complexion of the ensemble changes as more talented members enter, rules and values alter as the membership in the ensemble changes, and new repertoire and approaches to concert programming, rehearsal strategies, and auditioning procedures, among others, fuel further changes in ensemble membership. Charter members leave the ensemble when they cannot keep pace with, or do not wish to participate in, an organization in which higher demands are made of them. As the ensemble becomes more elitist, new members who wish to perform within this context replace others who leave, and the demand for places in the ensemble outstrips the supply. At maturation, change orientation is relatively low. Expectations based on past experience of the ensemble are well-defined, and as the ensemble is preoccupied with preserving its image, there is relatively little interest in changing its goals and programs. This does not mean to say that the ensemble is not adapting to changes in its environment, but rather, that there is an orientation to stability rather than to change. During regression, there is a relatively high change orientation as the ensemble seeks to recapture its past glory and prevent the steady attrition from its ranks. At cessation, there is relatively little change orientation as the ensemble simply seeks to survive in the present. Morale is low, and members are not constrained to develop programs for an ensemble with an uncertain future.

At formation, the reference group, or the group which ensemble members take to be the exemplary source of values and rules, is outside the ensemble. Given a collective group response to recruitment, low ensemble morale and prestige, and extrinsic motivation, the responses of these individuals to the ensemble are of primary importance in attracting members. In the expansion phase, motivation is increasingly intrinsic, ensemble morale and prestige value increase, and the reference group shifts within the ensemble. The recruitment of better musicians reinforces this tendency and leaves fewer relevant "others" outside the ensemble whose opinions must be taken into account. During maturation, an intra-ensemble reference group emerges, further enhancing the prestige value of the ensemble. In regression, the loss of key musicians from the ensemble, and the decline of prestige value 
reinforces the increasing importance of a reference group which is outside the ensemble. At cessation, this trend consolidates, with a reference group primarily outside the ensemble, and the departure of members when they sense themselves compromised by ensemble membership.

At formation, internal competition, or the striving between ensemble members for the available scarce resources, is comparatively low as members cooperate for the survival of the ensemble. During expansion, competition increases as the demand for available places outstrips the supply. At maturation, the competition among members for places in the group, together with the inclusion of individuals who have become members of the ensemble for individualistic reasons and have been motivated by intrinsic rewards, results in a comparatively high level of competition among ensemble members. During regression, there is a decline in competition, as an increasing supply of available places in the ensemble is not matched by an increase in demand for them. Some of the most talented musicians depart as the ensemble becomes progressively more universalistic and standards of excellence decline. At cessation, competition is relatively low as members are preoccupied with the survival of the ensemble, and there is a large supply of available ensemble places and a small demand for them.

Conversely, at formation, cooperation, or the collaboration between members for the purpose of attaining the ensemble objectives, is high, as members work together for the ensemble's survival. During expansion, there is declining cooperation as the ensemble becomes progressively more elitist and demand for the diminishing number of available places in the ensemble increases. At maturation, cooperation among members is relatively low as they seek to maintain their ensemble membership in the face of a small supply of places and a large demand for them. The ensemble members who join during expansion and maturation when a tendency to elitism prevails, are intrinsically motivated, respond individually rather than collectively, and are less prone to cooperate with others at the same level as that observed during the formation phase. During regression, as the ensemble's prestige value declines, the supply of available places increases, and members having elitist values depart and are replaced by less talented members under a universalistic philosophy, cooperation increases to a relatively high level at cessation, where the remaining members are needed to fill the ensemble complement. 
Eventually, even this level of cooperation is insufficient to overcome the low morale and prestige value and to ensure the ensemble's survival.

At formation, conductor choice, or the degree of freedom the conductor has in such areas as the admission of members to the ensemble and the determination of the ensemble program, is comparatively low. The conductor must accept members to fill the ensemble complement in the face of low community interest, prestige value and morale, and a comparatively small demand for the available places in the ensemble. During expansion, as the prestige value rises, and the demand for the available ensemble places increases, the conductor has greater choice in the acceptance of ensemble members. At maturation, with the prevailing elitism, and high prestige value and demand for ensemble places, the conductor has a comparatively high degree of choice. During regression, as it becomes increasingly difficult to attract high caliber members in the face of growing attrition from the ensemble, the conductor's choice diminishes until at cessation, he or she has very little choice.

\section{Aesthetics}

The aesthetic dimension refers to the underlying artistic philosophy and values prevailing in a social group; the acceptable standards of composition and performance, the adopted genres of artistic expression, and the degree to which aesthetic values dominate over other values, be they social, religious, or ethical. In particular, the accepted standards of artistic expression in musical performance constitute a central aesthetic consideration. They determine, for example, the eligibility of musicians for ensemble membership, the ensemble repertoire and concert programming, and the level of excellence expected of ensemble performance.

At formation, standards are comparatively ill-defined. Expectations of the ensemble's potential are unclear. The capacity of the ensemble is partly delimited by the quality of musicians recruited and the ability of the conductor. During expansion, expectations become clearer, and aesthetic standards progressively better defined. This process consolidates during maturation, as aesthetic standards are evidenced by the ensemble's past performance. During regression, when expectations are not realized, aesthetic standards become increasingly unclear, until at cessation, they are ill-defined. 
The progressive trend during formation and expansion toward aesthetic definition at maturation, and away from it during regression and cessation, contributes to the attraction and attrition, respectively, of ensemble members who are attracted by elitist values and intrinsically motivated. It is these individuals who can contribute most to the achievement of aesthetic excellence in the context of a balance of values, be they social, moral, or religious.

In summary, the characteristic dimensions for each of the five phases of ensemble development have been described. A profile of characteristics for each of these phases emerges, enabling a systematic comparison of them using criteria that are common to all phases.

\section{III}

I will now derive recruitment strategies that are consistent with, and characteristic of, each of the five ensemble development phases described above. Recruitment is envisaged as a dynamic process, flowing from and feeding into each ensemble development phase.

\section{Formation}

At formation, there is some flexibility with respect to aspects of the timing of rehearsals, performances and ensemble place openings, the rehearsal venue, the size and composition of the ensemble, the repertoire to be performed, and the values and rules adopted by the ensemble. The rehearsal venue is within easy travelling distance of the ensemble members' homes and recruitment is focused on this relatively small geographic area. As a feeder system is not well established, external competition is high, and there is a relatively high turnover rate of members, recruitment is actively pursued and a high priority task.

The "demonstration effect" is operative, whereby community interest, ensemble morale, and demand for ensemble membership increase over time as the nature and quality of ensemble rehearsals and performances are evidenced. As a result, the process of image building or personification constitutes an important element of recruitment, and effort is directed toward the attainment of desired aesthetic standards and the establishment of the ensemble's reputation and prestige value. 
Recruitment strategies emphasize the extrinsic rewards of ensemble membership for the relevant target population. In particular, selective recruitment of those individuals and groups who are most likely to influence the target population and bring prestige to the ensemble is undertaken, with the principal emphasis on "selling" the conductor's reputation. Direct recruitment is principally initiated by the director, who elicits the cooperation of ensemble members, utilizes their informal social networks, and attempts to gain influence with the influential "others" who comprise the reference group outside the ensemble.

\section{Expansion}

At expansion, recruitment procedures are standardized and concentrated in shorter specified times, and recruitment is directed over a wider geographic area than that in the formation phase. Rules are more clearly defined, and while there is some flexibility as expansion proceeds, individuals are recruited on the basis of these rules and they increasingly accept them as given. A formalized feeder system of recruitment is established to provide preparatory training for the ensemble and as a means whereby members can readily be recruited. Also, there is an increasing reliance on indirect recruitment, for example, ensemble performances and recruitment by ensemble members among their informal social networks of families and friends, rather than on direct recruitment, for example, advertising for musicians.

As the size and composition of the ensemble is defined, and an increasing demand for membership in the ensemble together with a lower turnover rate enables greater selectivity in the choice of applicants, more highly qualified musicians are recruited and auditioning procedures assume a greater importance in the selection of ensemble members. This results in problems of reduced cooperation and increased competition among ensemble members, problems that must be balanced against gains in greater conductor choice with respect to ensemble members, repertoire selection and concert programming, improved talent as the ensemble increasingly emphasizes elitist values and recruitment strategies are designed to appeal to the "others" who share these values and constitute the new target population, and better definition of aesthetic standards.

Recruitment strategies increasingly emphasize the intrinsic rewards of ensemble membership, for example, musical repertoire to be performed. Image preservation, with an emphasis on 
highlighting the past performance of the ensemble and its growing reputation, constitutes an increasingly important element of these strategies. Also, the reputation and prestige of the ensemble along with that of the conductor are increasingly emphasized.

\section{Maturation}

At maturation, recruitment is concentrated in short periods of time, and rehearsal, performance and audition procedures are well known. Members are recruited from a wide geographic area, for example, city or region, and formal and informal feeder systems are well established, bringing in a steady stream of new recruits when openings exist. Recruitment is principally initiated by the ensemble members rather than the conductor, and indirect recruitment through feeder systems rather than direct recruitment through advertising is emphasized. Rules are well defined and recruits accept them as given or fixed.

A well defined ensemble size with a low turnover rate and a high demand by qualified musicians for the available ensemble places, results in a high degree of importance to the auditioning of recruits, and a waiting list for the ensemble. In order to hold the ensemble together as a workable organization, the comparatively high levels of competition and low levels of cooperation between ensemble members necessitate administrative and organizational policies designed to promote group cohesion and goal seeking. These problems must be traded off against the high degree of conductor choice of ensemble members, and the well defined and comparatively high aesthetic standards of the ensemble.

Recruitment strategies emphasize the intrinsic rewards of ensemble membership, for example, musical repertoire to be performed, and attract others in the target population who share elitist values. Image preservation based on the past record of the ensemble is the focus of the recruitment strategies, and the principal emphasis is upon "selling" the prestige and reputation of the ensemble rather than that of the conductor.

\section{Regression}

At regression, recruitment increasingly is an ongoing activity throughout the year, with growing flexibility in the size and composition of the ensemble, the timing of rehearsals, performances, and available openings in the ensemble, and the rules of the ensemble, among others. Members are recruited from a shrinking area and the informal and formal feeder systems of recruitment 
break down. Direct recruitment through advertising assumes growing prominence as a source of new recruits, and as morale declines, recruitment is decreasingly initiated by ensemble members through their social networks, and increasingly, by the director of the ensemble.

An increasing turnover rate and diminishing demand for places in the ensemble result in the declining importance of auditions and an increasing flexibility in admission standards. More and more, recruitment strategies highlight universalistic values designed to fill the complement of singers in the ensemble. As a result, the conductor has diminishing choice in respect of ensemble membership, repertoire selection and concert programming, and aesthetic standards are decreasingly well defined and on the decline.

Recruitment strategies increasingly emphasize the extrinsic rewards of ensemble membership and focus on image building or personification. Selling the conductor's prestige and reputation becomes increasingly necessary. With the growing importance of a reference group outside the ensemble, the conductor increasingly cultivates influence with the influential "others" outside the ensemble who constitute this group.

\section{Cessation}

At cessation, recruitment is an ongoing preoccupation of the ensemble, precluding an adequate prediction and planning of its program. The informal and formal feeder systems of recruitment break down. Ensemble members are principally recruited from a relatively small geographic area. The high turnover rate and continual influx of new members disrupts group cohesion, reduces morale, and necessitates a flexibility in rules so as to prevent further attrition. With a low demand for the available places in the ensemble, there is little emphasis on auditioning new members, and a resulting flexibility in admission standards.

In spite of efforts to stress a cooperative recruitment effort on the part of ensemble members, direct recruitment is primarily initiated by the director. Universalistic values designed to attract the complement of musicians for the ensemble are stressed, with the result that the conductor has limited choice of ensemble members, repertoire selection and concert programming, and aesthetic standards are necessarily ill defined and comparatively low.

Recruitment strategies emphasize the extrinsic rewards of 
ensemble membership and focus on personification. Selling the conductor's reputation is a central task. In spite of the director's efforts to influence the reference group outside the ensemble, the past record and decline of the ensemble militates against success, and the negative ensemble image in the community makes the task of successful recruitment even more difficult.

\section{IV}

The analysis has various implications for research and practice. For research, it constitutes a conceptual framework for the systematic gathering of empirical evidence on ensemble development phases and their associated recruitment strategies. The theoretical characteristics outlined above may be present in greater or lesser degree in the real world, and some features may not be evident or important in any given situation - a function of the use of theoretical types - nevertheless, the analysis merits systematic testing. Such research is useful in clarifying and evaluating the theoretical ideas that have been described, and in contributing in a systematic way to an understanding of the recruitment process in amateur ensembles. In particular, case studies of typical or representative amateur ensembles provide a useful means by which this evidence can be amassed. Ensemble directors can make a significant contribution in this regard by recording their observations on the application of various recruitment strategies under specified conditions and their analyses of the positive and negative implications of these strategies for ensemble development.

Also, various issues excluded from the present analysis merit investigation, including: the variety of ensemble development curves that have been historically evident and the factors responsible in each case; the impact of differences among sponsoring organizations and genres of ensembles, on ensemble development and the associated recruitment strategies; recruitment in small ensembles that are cooperatively organized rather than directed by an individual appointed for such a purpose; recruitment in ensembles where membership is required or prescribed and is not a matter of choice for the director and/or members, and the implications for ensemble development; recruitment in professional and quasi-professional ensembles and comparative studies of recruitment as between these and amateur 
ensembles; and the impact of external influence on ensemble development phases and the recruitment process.

For practice, the analysis constitutes a conceptual framework in which ensemble directors can identify the relevant phase of development for their ensembles and devise appropriate recruitment strategies. The different problems and preoccupations of directors at each phase are underscored in the analysis: in formation, with attempting to establish the ensemble and move it toward expansion; in expansion, with building a solid basis for maturation; in maturation, with sustaining the ensemble so as to prevent regression; in regression, with rejuvenating the ensemble or reversing the movement toward cessation; and in cessation, with the necessity of reforming the ensemble or abandoning it altogether.

Recruitment not only assumes a different significance and manifestation at each ensemble development phase, but given that recruitment strategies feed into as well as flow from each phase, they become as much a part of the process whereby a change in the ensemble phase is orchestrated, as the manifestation of each phase. For example, a director with an ensemble in regression who wishes to move it toward expansion, may adopt recruitment strategies consistent with expansion as part of the process of rejuvenating the ensemble. 


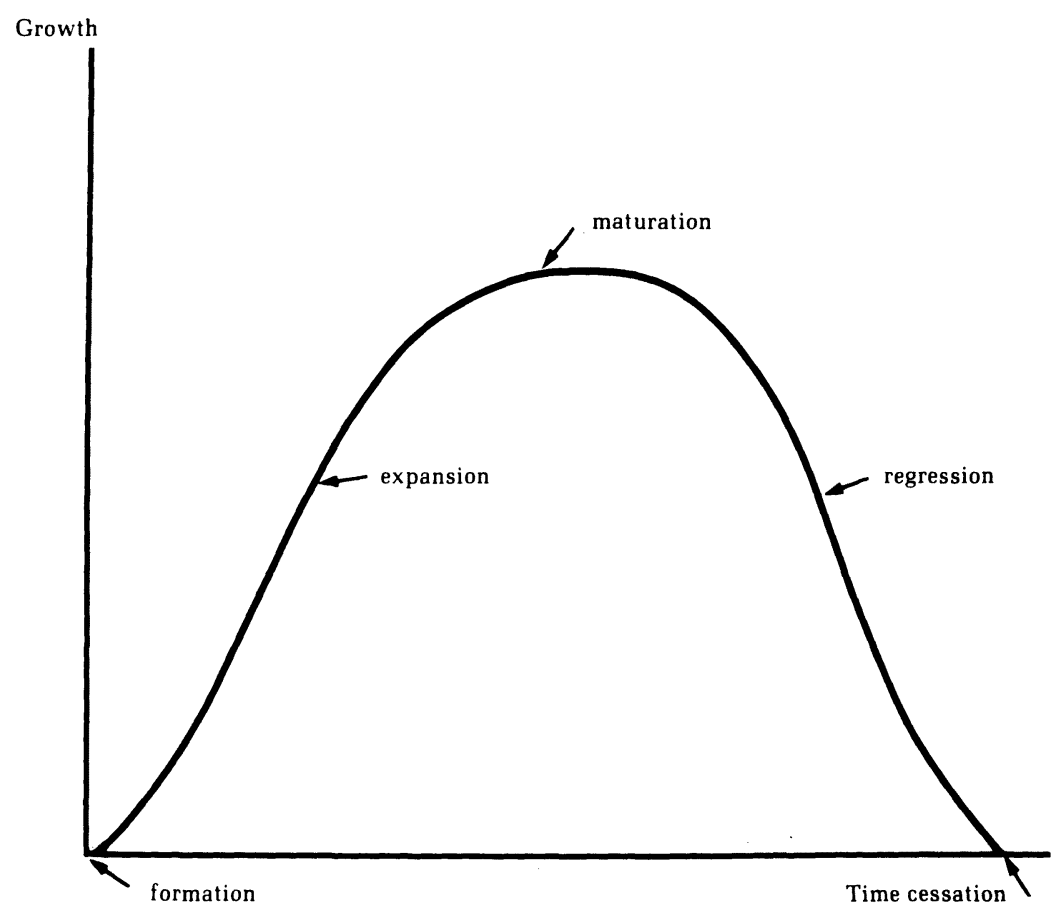

Figure 1

Phases in the development of an ensemble 


\begin{tabular}{|c|c|c|c|c|c|}
\hline DIMENSIONS & FORMATION & EXPANSION & MATURATION & REGRESSION & CESSATION \\
\hline $\begin{array}{l}\text { Time } \\
\text { Rehearsals } \\
\text { Performances } \\
\text { Availability of places } \\
\end{array}$ & $\begin{array}{l}\text { ill-defined } \\
\text { ill-defined } \\
\text { ill-defined } \\
\end{array}$ & $\begin{array}{l}\text { increasing definition } \\
\text { increasing definition } \\
\text { increasing definition }\end{array}$ & $\begin{array}{l}\text { well-defined } \\
\text { well-defined } \\
\text { well-defined }\end{array}$ & $\begin{array}{l}\text { decreasing definition } \\
\text { decreasing definition } \\
\text { decreasing definition }\end{array}$ & $\begin{array}{l}\text { ill-defined } \\
\text { ill-defined } \\
\text { ill-defined }\end{array}$ \\
\hline $\begin{array}{l}\text { Space } \\
\text { Feeder area } \\
\text { Feeder system } \\
\text { External competition } \\
\end{array}$ & $\begin{array}{l}\text { small } \\
\text { ill-defined } \\
\text { high }\end{array}$ & $\begin{array}{l}\text { increasing } \\
\text { increasing definition } \\
\text { decreasing }\end{array}$ & $\begin{array}{l}\text { large } \\
\text { well-defined } \\
\text { low }\end{array}$ & $\begin{array}{l}\text { decreasing } \\
\text { decreasing definition } \\
\text { increasing }\end{array}$ & $\begin{array}{l}\text { small } \\
\text { ill-defined } \\
\text { high }\end{array}$ \\
\hline $\begin{array}{l}\text { Number } \\
\text { Size of ensemble } \\
\text { Demand for places } \\
\text { Supply of places } \\
\end{array}$ & $\begin{array}{l}\text { ill-defined } \\
\text { small } \\
\text { large } \\
\end{array}$ & $\begin{array}{l}\text { increasing definition } \\
\text { increasing } \\
\text { decreasing }\end{array}$ & $\begin{array}{l}\text { well-defined } \\
\text { large } \\
\text { small } \\
\end{array}$ & $\begin{array}{l}\text { decreasing definition } \\
\text { decreasing } \\
\text { increasing }\end{array}$ & $\begin{array}{l}\text { ill-defined } \\
\text { small } \\
\text { large }\end{array}$ \\
\hline $\begin{array}{l}\text { Causation } \\
\text { Community interest } \\
\text { Ensemble morale } \\
\text { Motivation } \\
\text { Response } \\
\text { Image } \\
\text { Prestige source } \\
\text { Prestige focus } \\
\text { Prestige value } \\
\end{array}$ & $\begin{array}{l}\text { low } \\
\text { low } \\
\text { extrinsic } \\
\text { collective } \\
\text { personification } \\
\text { individual } \\
\text { conductor-centered } \\
\text { low } \\
\end{array}$ & $\begin{array}{l}\text { increasing } \\
\text { increasing } \\
\text { increasing intrinsic } \\
\text { increasing individualism } \\
\text { increasing preservation } \\
\text { increasing ensemble } \\
\text { increasing ensemble-centered } \\
\text { increasing }\end{array}$ & $\begin{array}{l}\text { high } \\
\text { high } \\
\text { intrinsic } \\
\text { individualistic } \\
\text { preservation } \\
\text { ensemble } \\
\text { ensemble-centered } \\
\text { high } \\
\end{array}$ & $\begin{array}{l}\text { decreasing } \\
\text { decreasing } \\
\text { decreasing intrinsic } \\
\text { decreasing individualism } \\
\text { decreasing preservation } \\
\text { decreasing ensemble } \\
\text { decreasing ensemble-centered } \\
\text { decreasing }\end{array}$ & $\begin{array}{l}\text { low } \\
\text { low } \\
\text { extrinsic } \\
\text { collective } \\
\text { personification } \\
\text { individual } \\
\text { dconductor-centered } \\
\text { low } \\
\end{array}$ \\
\hline $\begin{array}{l}\text { Ethic } \\
\text { Values } \\
\text { Rules } \\
\text { Change orientation } \\
\text { Reference group } \\
\text { Internal competition } \\
\text { Cooperation } \\
\text { Conductor choice } \\
\end{array}$ & $\begin{array}{l}\text { universalistic } \\
\text { ill-defined } \\
\text { low } \\
\text { extra-ensemble } \\
\text { low } \\
\text { high } \\
\text { low } \\
\end{array}$ & $\begin{array}{l}\text { increasing elitism } \\
\text { increasing definition } \\
\text { high } \\
\text { increasing intra-ensemble } \\
\text { increasing } \\
\text { decreasing } \\
\text { increasing }\end{array}$ & $\begin{array}{l}\text { elitist } \\
\text { well-defined } \\
\text { low } \\
\text { intra-ensemble } \\
\text { high } \\
\text { low } \\
\text { high } \\
\end{array}$ & $\begin{array}{l}\text { decreasing elitism } \\
\text { decreasing definition } \\
\text { high } \\
\text { decreasing intra-ensemble } \\
\text { decreasing } \\
\text { increasing } \\
\text { decreasing }\end{array}$ & $\begin{array}{l}\text { universalistic } \\
\text { ill-defined } \\
\text { low } \\
\text { extra-ensemble } \\
\text { low } \\
\text { high } \\
\text { low } \\
\end{array}$ \\
\hline $\begin{array}{l}\text { Aesthetic } \\
\text { Standards }\end{array}$ & ill-defined & increasing definition & well-defined & decreasing definition & ill-defined \\
\hline
\end{tabular}

Figure 2

A comparison of the characteristics of ensemble development phases 


\section{NOTES}

1. Zentner (1973: 134), has described recruitment, the process of attracting new members to either form groups or replace the natural attrition from them over time, as one of twenty-two processes which are applicable to all social organizations and determined by "norm sets" governing "the number of membership categories which shall be permitted to exist, the definition of the rights of each category, and the criteria which must be met in order to be admitted."

2. The definition of an amateur musician is problematic. In his article entitled, "Music Among Friends: The Social Networks of Amateur Musicians" (1976), Robert A. Stebbins has dealt with some of these problems from a sociological perspective, arguing that "the essence of amateurism lies in the social and attitudinal organization of its practitioners." He claims that it is misleading to conceive of amateurs as distinguished from professionals simply on the basis of the amount of time spent on, or income earned in, music. Rather, the distinction is more broadly based in terms of an occupational "continuance" commitment an orientation either to music, or outside it, as a basis of one's livelihood. At best, the distinctions between amateur and professional are unclear, representing types, or theoretical constructs which in reality are less clearly distinguished.

3. The terms "conductor" and "director" are used interchangeably in this analysis to refer to the individual charged with the musical leadership and artistic direction of the ensemble.

4. These conditions correspond to Type I musical instruction described in Jorgensen (1981).

5. A useful discussion of the process of typification in sociology is found in Zentner (1979a).

6. For an illustrative use of these characteristic dimensions in a systematic analysis of two contrasting "world views" in curricular planning for sociological change, see Zentner (1979b).

7. The processes of personification and image preservation are described in Zentner (1973: 138-39; 163-65). 


\section{REFERENCES}

JORGENSEN, E.R.

1981: "On a Choice-based Instructional Typology in Music," Journal of Research in Music Education, XXIX/2, 97-102.

LEVINGER, G.

1980: "Toward the Analysis of Close Relationships," Journal of STEBBINS, R.A. Experimental Social Psychology, XVI/6, 510-44.

1976: "Music Among Friends: The Social Networks of Amateur Musicians," International Review of Sociology, XII/1-2, 52-73.

ZENTNER, $\mathrm{H}$.

1973: Prelude to Administrative Theory. Calgary: Strayer.

1979a: "The Construction of Types and Standards in Sociology: A Critical Reassessment," The International Journal of Critical Sociology, III, 49-59.

1979b: "Curricular Planning for Sociocultural Change and Development: A Critique," The Journal of Educational Thought, XII/3 (1979), 170-97. 